
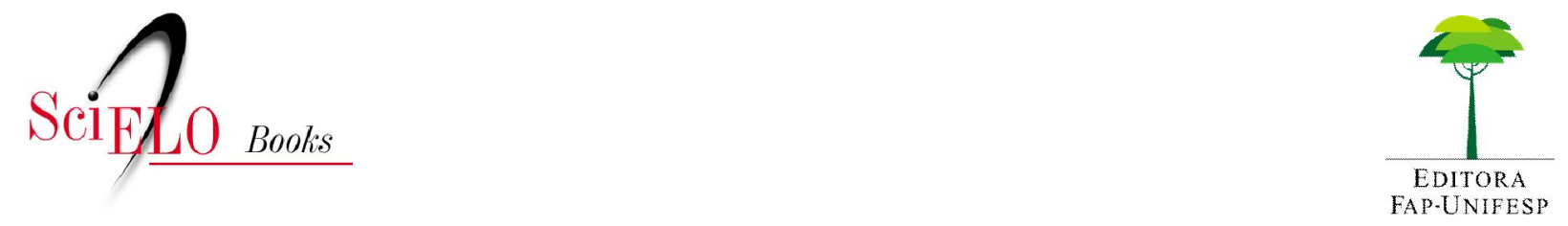

\title{
II - Lesões elementares no exame dermatológico
}

\author{
Douglas A. Rodrigues \\ Jane Tomimori \\ Marcos C. Floriano \\ Sofia Mendonça
}

RODRIGUES, DA., et al. Atlas de dermatologia em povos indígenas [online]. São Paulo: Editora Unifesp, 2010. Lesões elementares no exame dermatológico, p. 33-44. ISBN 978-85-61673-68-0. Available from SciELO Books $<$ http://books.scielo.org $>$.

\section{(1) $(1)(2)$}

All the contents of this work, except where otherwise noted, is licensed under a Creative Commons Attribution-Non Commercial-ShareAlike 3.0 Unported.

Todo o conteúdo deste trabalho, exceto quando houver ressalva, é publicado sob a licença Creative Commons Atribuição Uso Não Comercial - Partilha nos Mesmos Termos 3.0 Não adaptada.

Todo el contenido de esta obra, excepto donde se indique lo contrario, está bajo licencia de la licencia Creative Commons Reconocimento-NoComercial-CompartirIgual 3.0 Unported. 
II

LESÕES ELEMENTARES

NO EXAME DERMATOLÓGICO 

A descrição da lesão elementar permite direcionar o diagnóstico das doenças dermatológicas a partir do reconhecimento das lesões da pele e é parte fundamental do exame físico dermatológico. Definindo-se o diagnóstico é que se pode indicar o melhor tratamento do doente. A seguir, amostras dos exame dermatológicos de algumas lesões elementares mais encontradas nos povos indígenas, segundo a nossa observação no trabalho de campo.

\section{PÁPULA}

Lesão de conteúdo sólido, elevada, com tamanho menor que $1 \mathrm{~cm}$ (Figura 1 ).

\section{PLACA}

Lesão de conteúdo sólido, elevada, com tamanho maior que $1 \mathrm{~cm}$, geralmente de superfície plana (Figura 2).

\section{NÓDULO}

Lesão de conteúdo sólido, de formato arredondado ("caroço") que pode apresentar-se como uma elevação na pele ou como uma lesão mais profunda, com tamanho maior que $1 \mathrm{~cm}$ (Figura 3 ).

\section{VERRUCOSIDADE}

Lesão de conteúdo sólido, com superfície irregular e branco-amarelada (Figura 4).
vESÍCULA

Lesão de conteúdo líquido e claro, menor que $1 \mathrm{~cm}$ (Figura 5).

\section{BOLHA}

Lesão de conteúdo líquido, medindo mais de $1 \mathrm{~cm}$ (Figura 6).

\section{PÚSTULA}

Lesão de conteúdo purulento (amarelado), com menos de $1 \mathrm{~cm}$ (Figura 7).

\section{MANCHAS ERITEMATOSAS}

Alteração da cor, geralmente avermelhada, que desaparece quando se aperta a lesão (dígito-pressão) (Figura 8).

MANCHAS HIPOCRÔMICAS E ACRÔMICAS Alteração da cor da pele, que se torna mais clara que a pele normal (hipocromia) (Figura 9), ou com coloração totalmente branca (acromia) (Figura 10).

\section{MANCHAS HIPERCRÔMICAS}

Alteração da cor da pele, que se torna mais escura que a pele normal (Figura 11).

\section{EDEMA}

Extravasamento de líquidos nas camadas da pele, dando aspecto inchado, podendo se apresentar com a cor natural da pele ou com eritema (Figura 12). 
ÚLCERAS

Perda da solução de continuidade da pele ("ferida") (Figura 13).

ESCAMAS

Perda de camadas superficiais da pele ("descamação") (Figura 14).

\section{CROSTAS}

Lesões que recobrem áreas em que há perda de solução de continuidade da pele (úlceras ou bolhas rompidas). Funcionam como um "curativo biológico" (Figura 15). A crosta pode ser da cor de mel (melicérica) ou castanho-avermelhada (hemática).

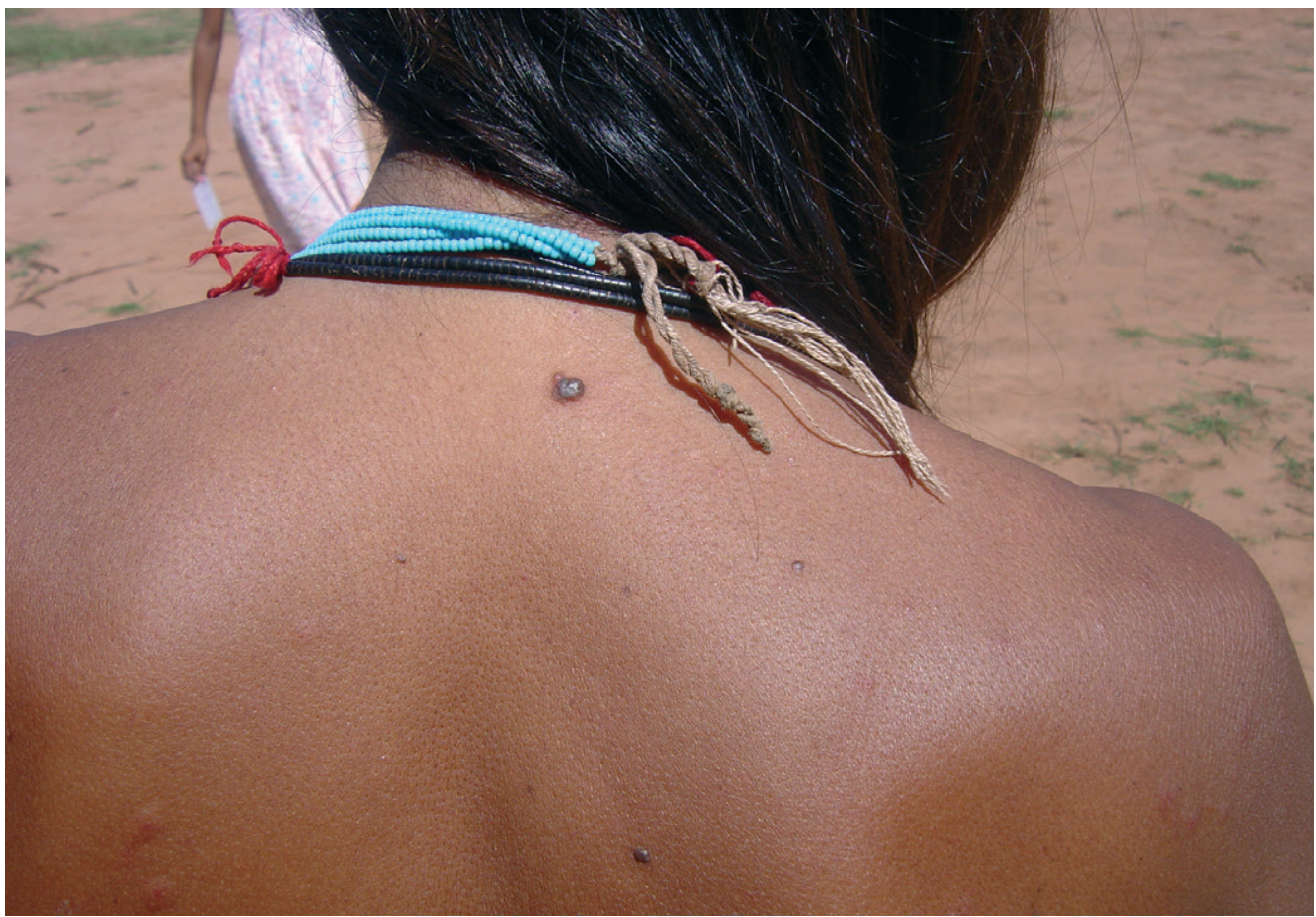

Figura 1. Pápulas na região dorsal. 


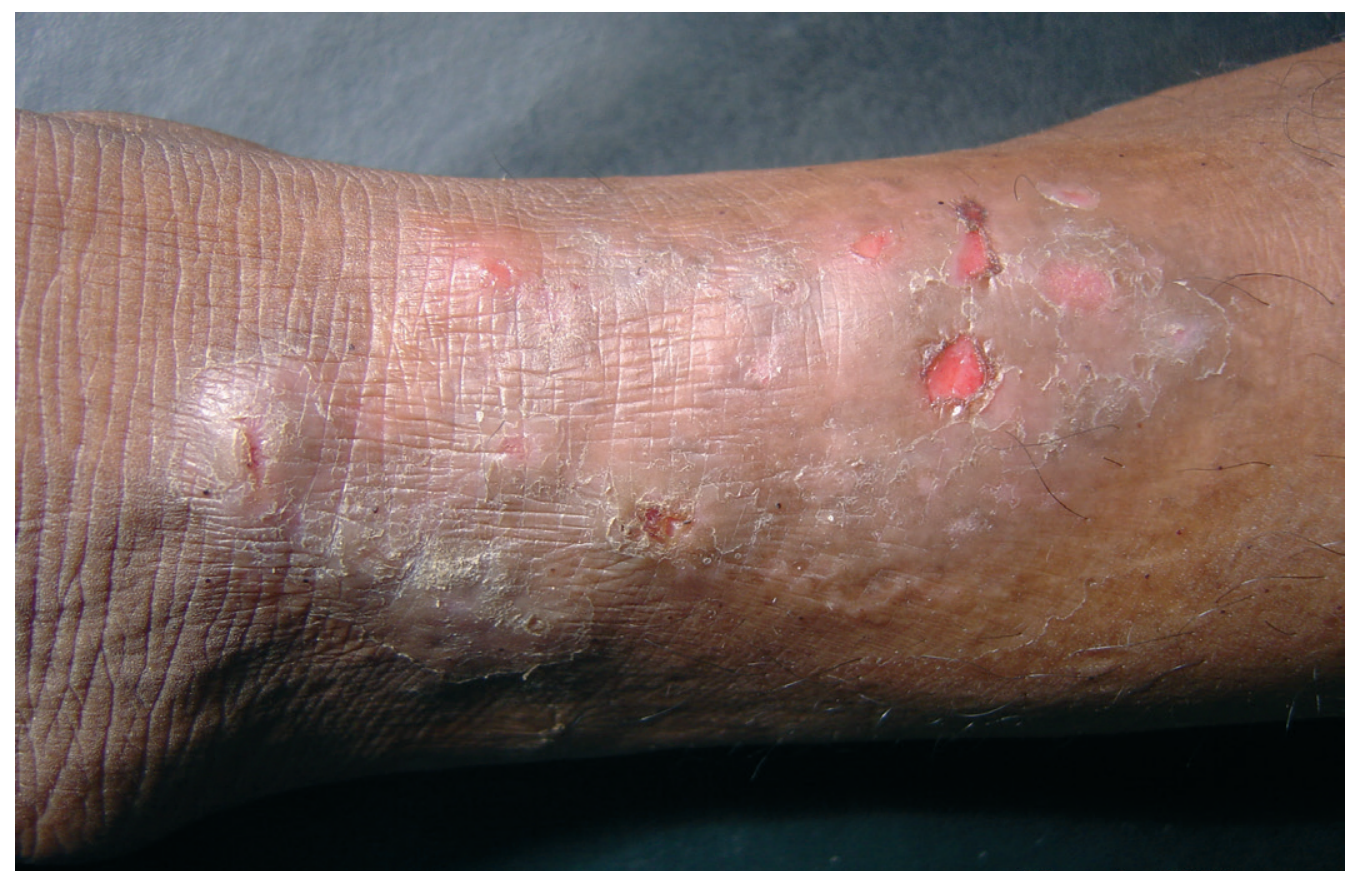

Figura 2. Placa com descamação e úlceras rasas na sua superfícies, localizada na perna.

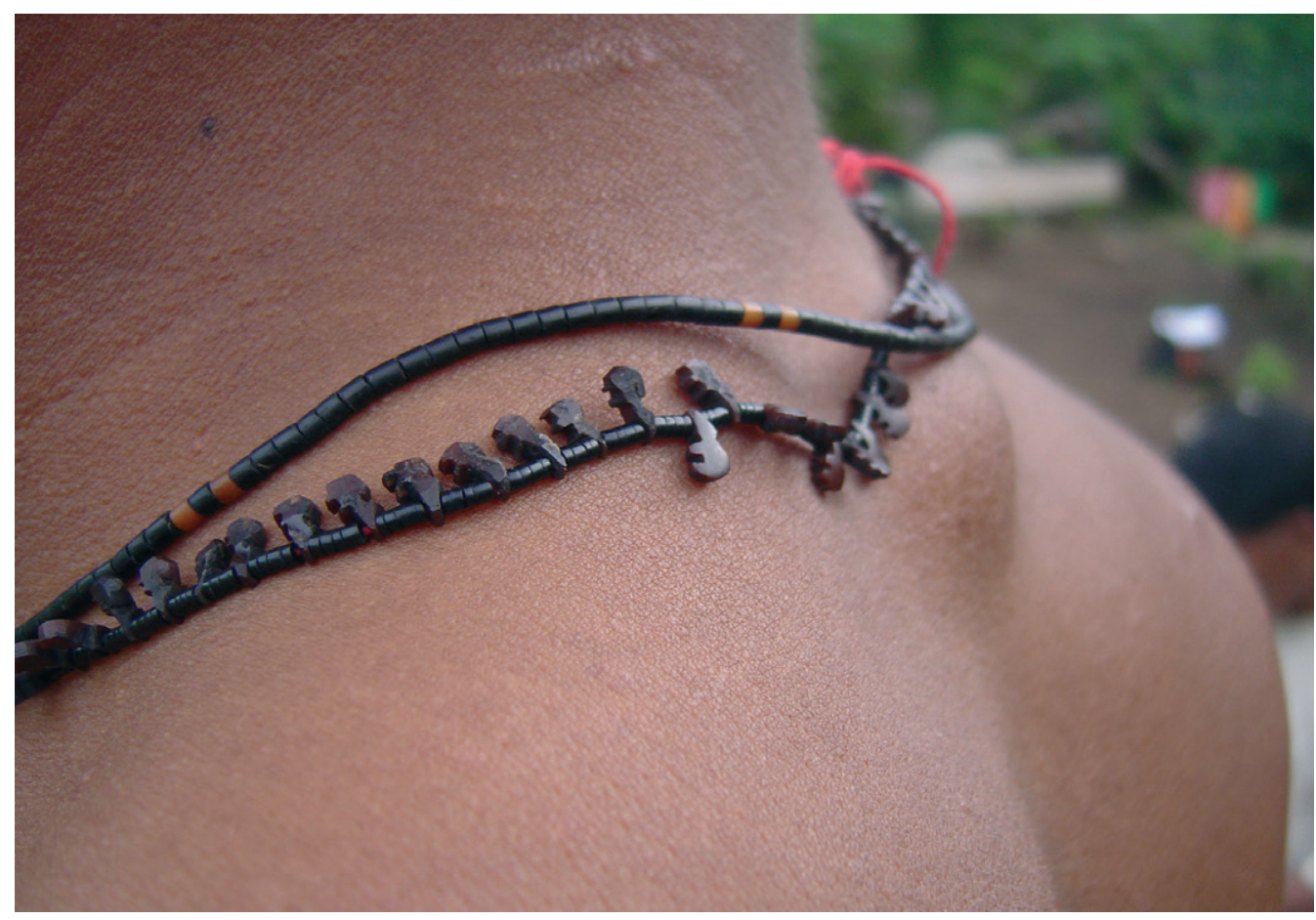

Figura 3. Nódulo recoberto por pele normal, na região cervical posterior. 


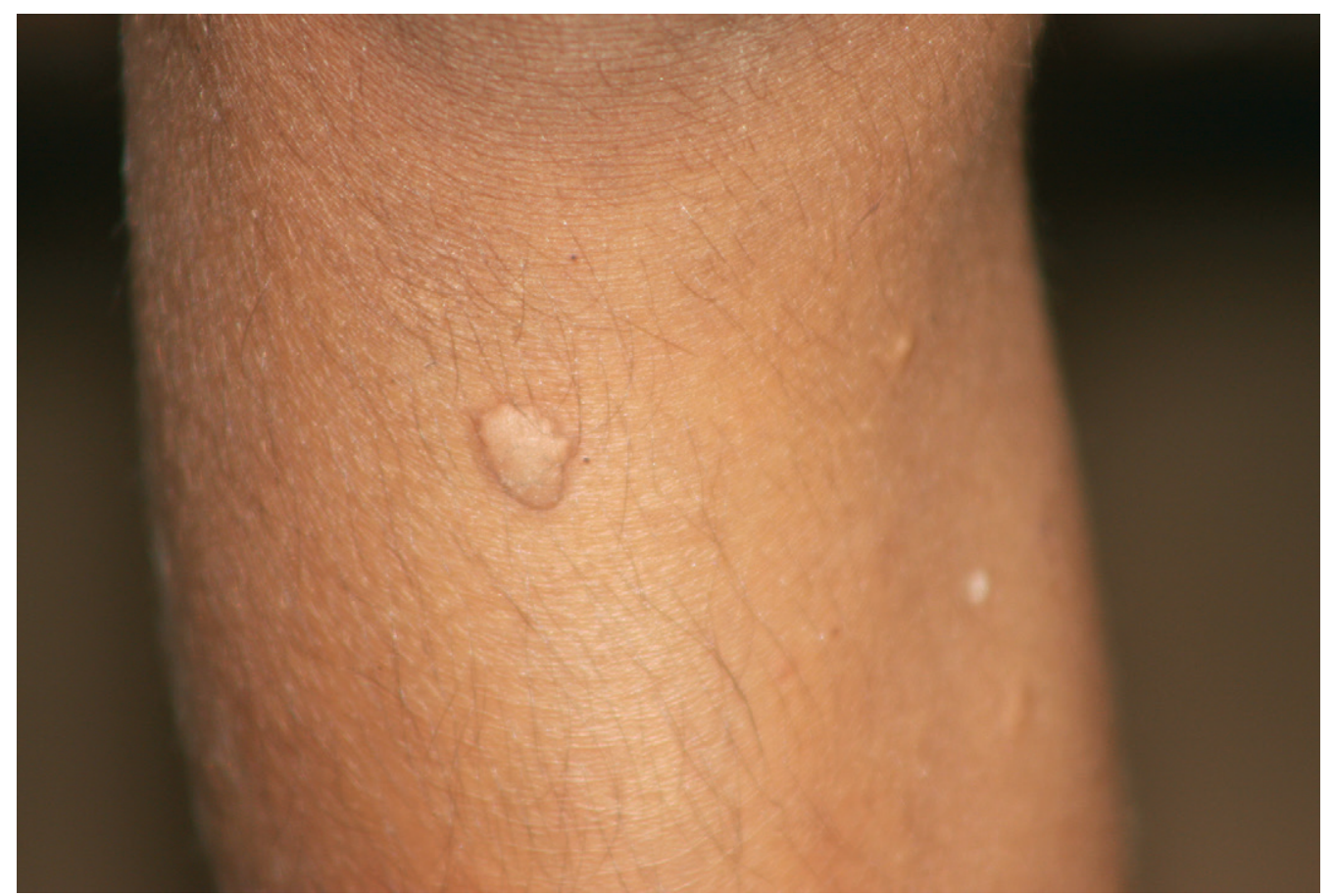

Figura 4. Verrucosidade (pápula com superfície verrucosa) na perna.

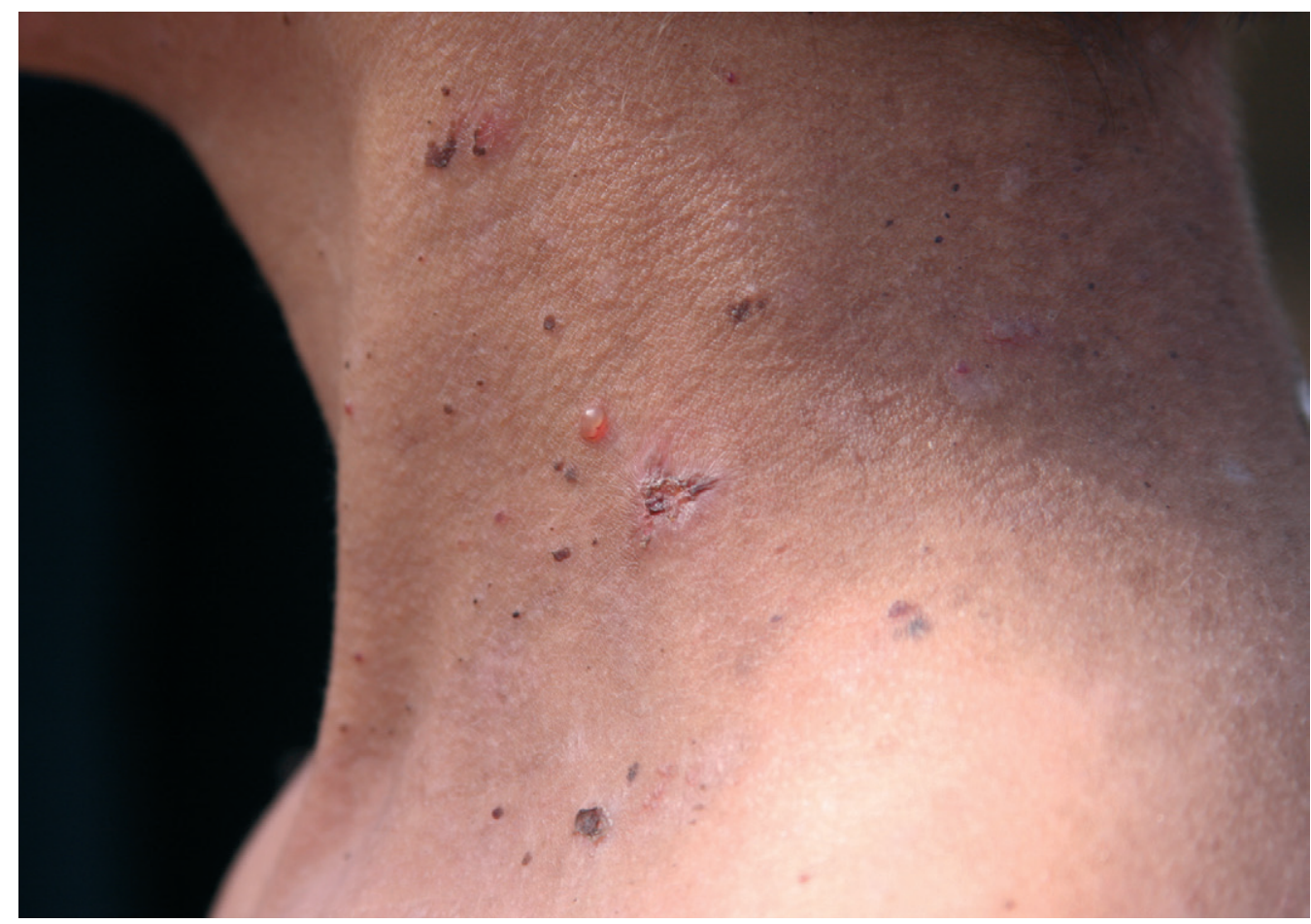

Figura 5. Vesícula no pescoço. 


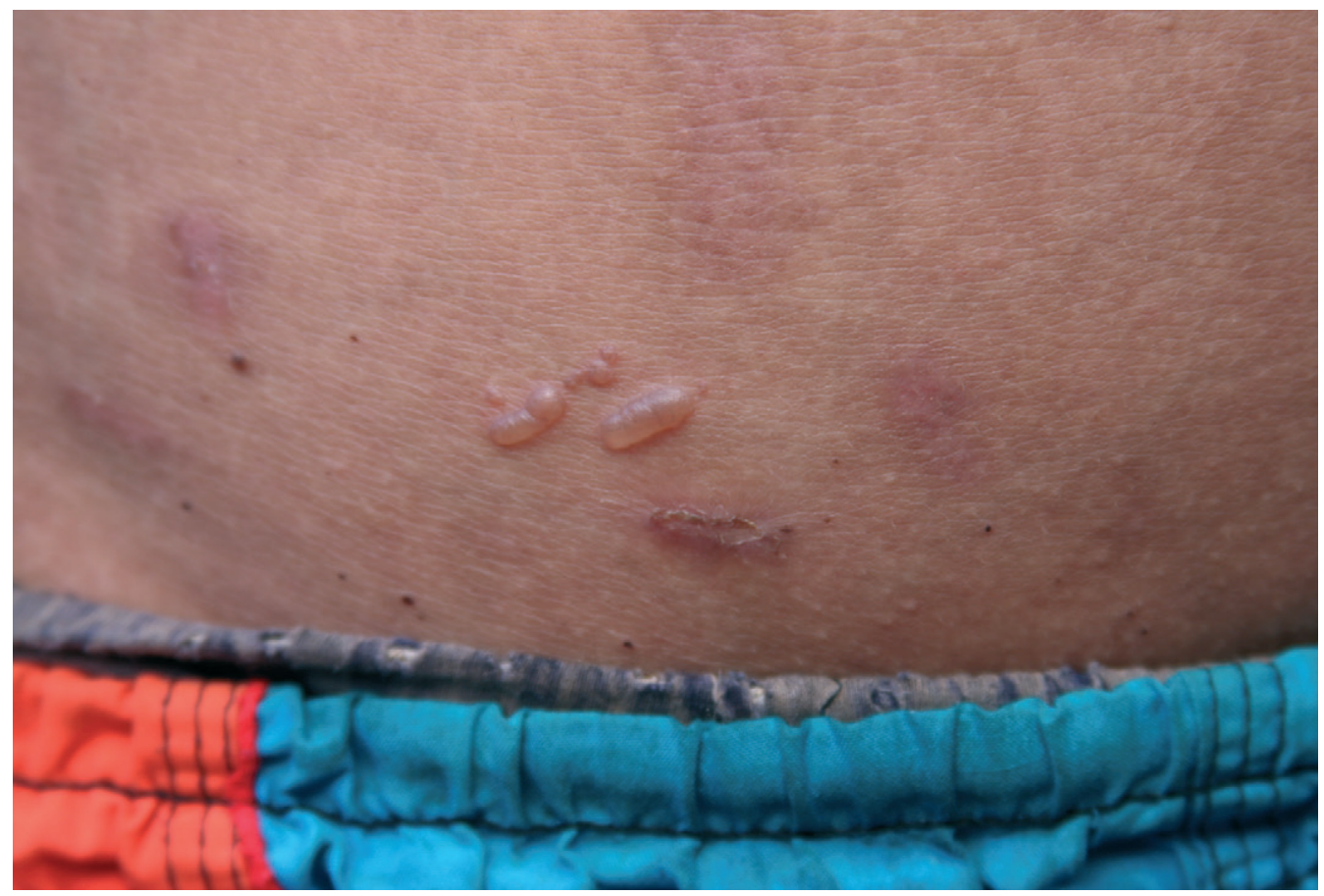

Figura 6. Bolhas de conteúdo claro no abdome.

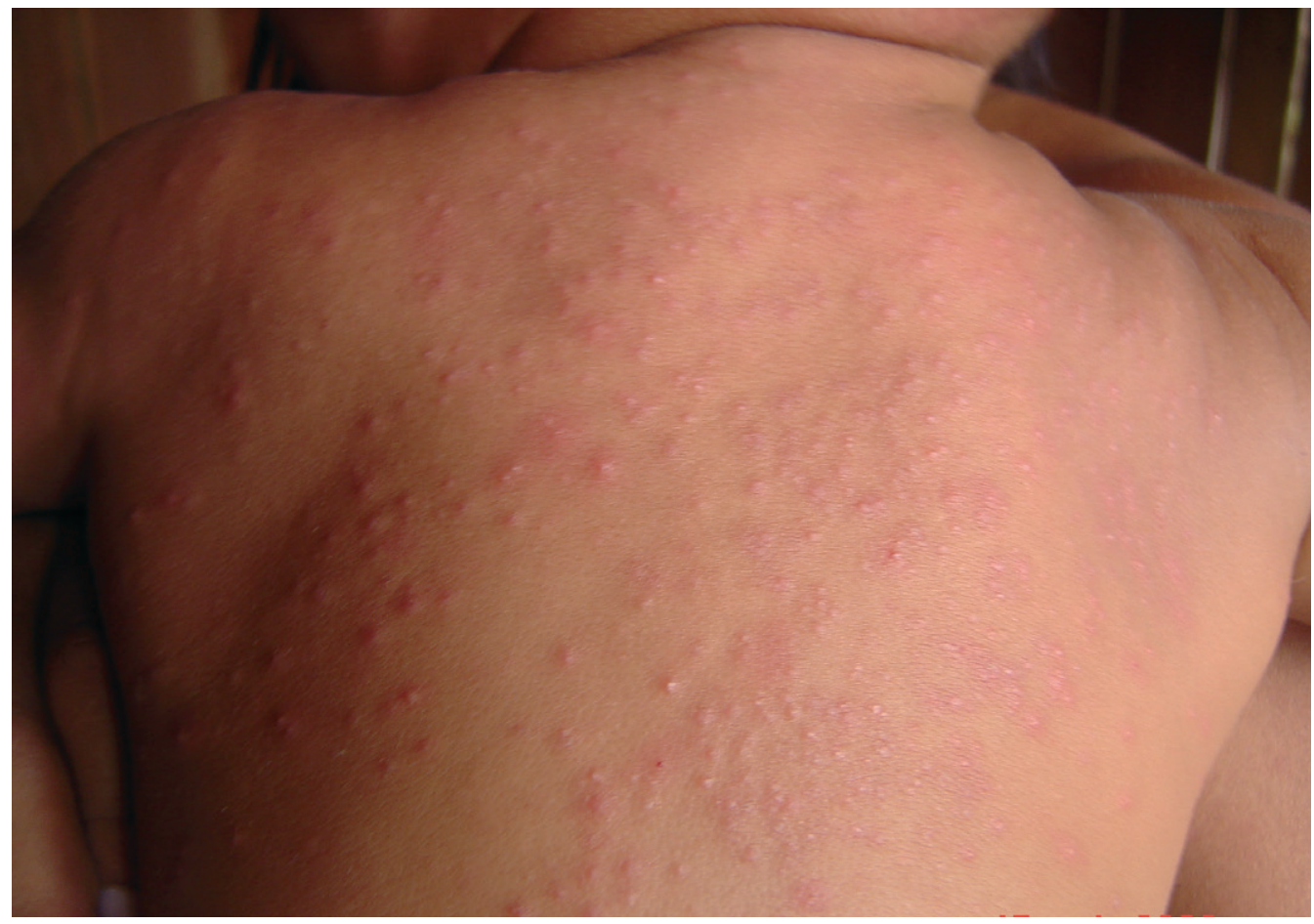

Figura 7. Pústulas sobre base eritematosa no dorso. 


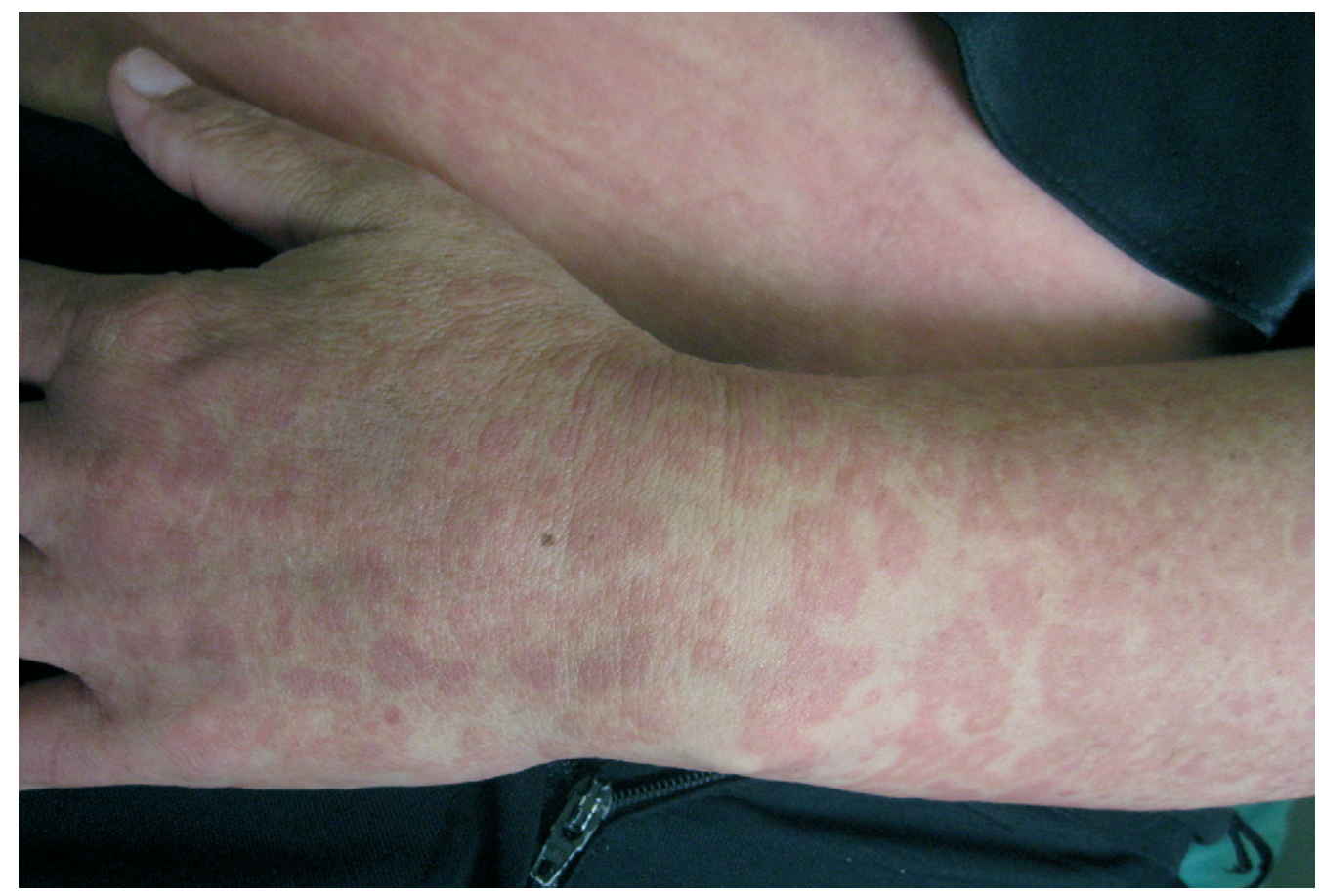

Figura 8. Manchas eritematosas no antebraço e no dorso da mão.

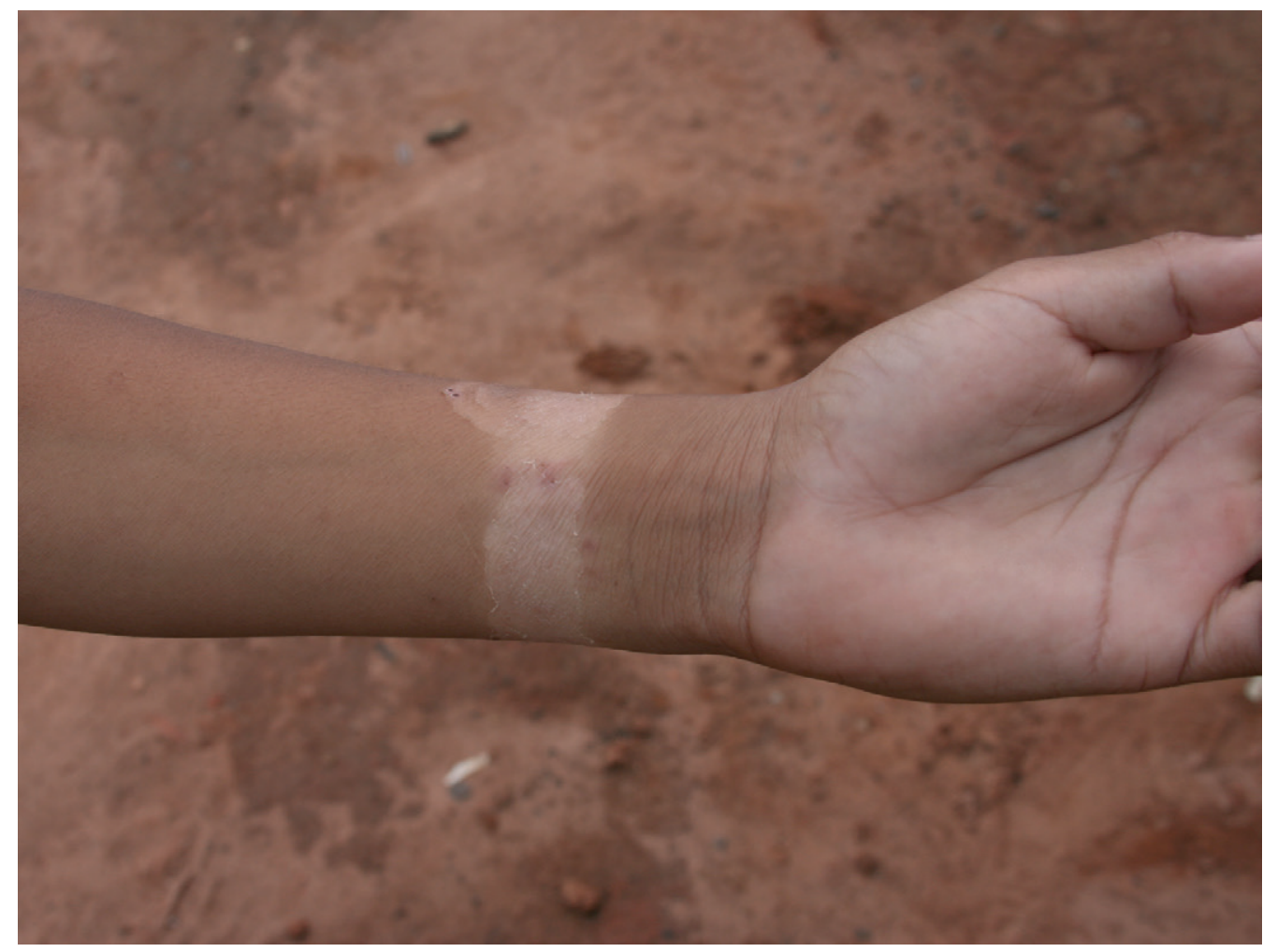

Figura 9. Mancha hipocrômica no antebraço. 


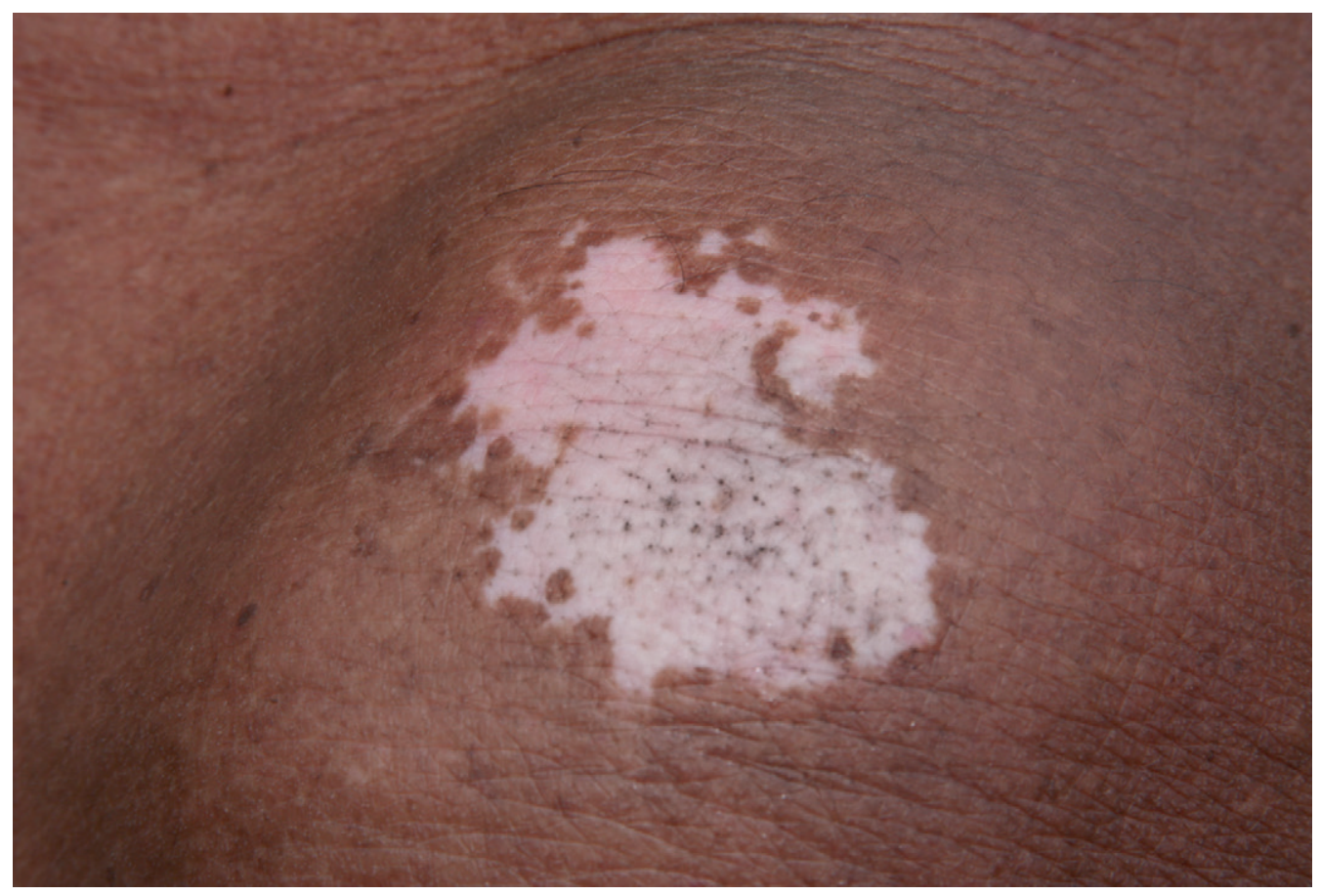

Figura 10. Mancha acrômica no ombro.

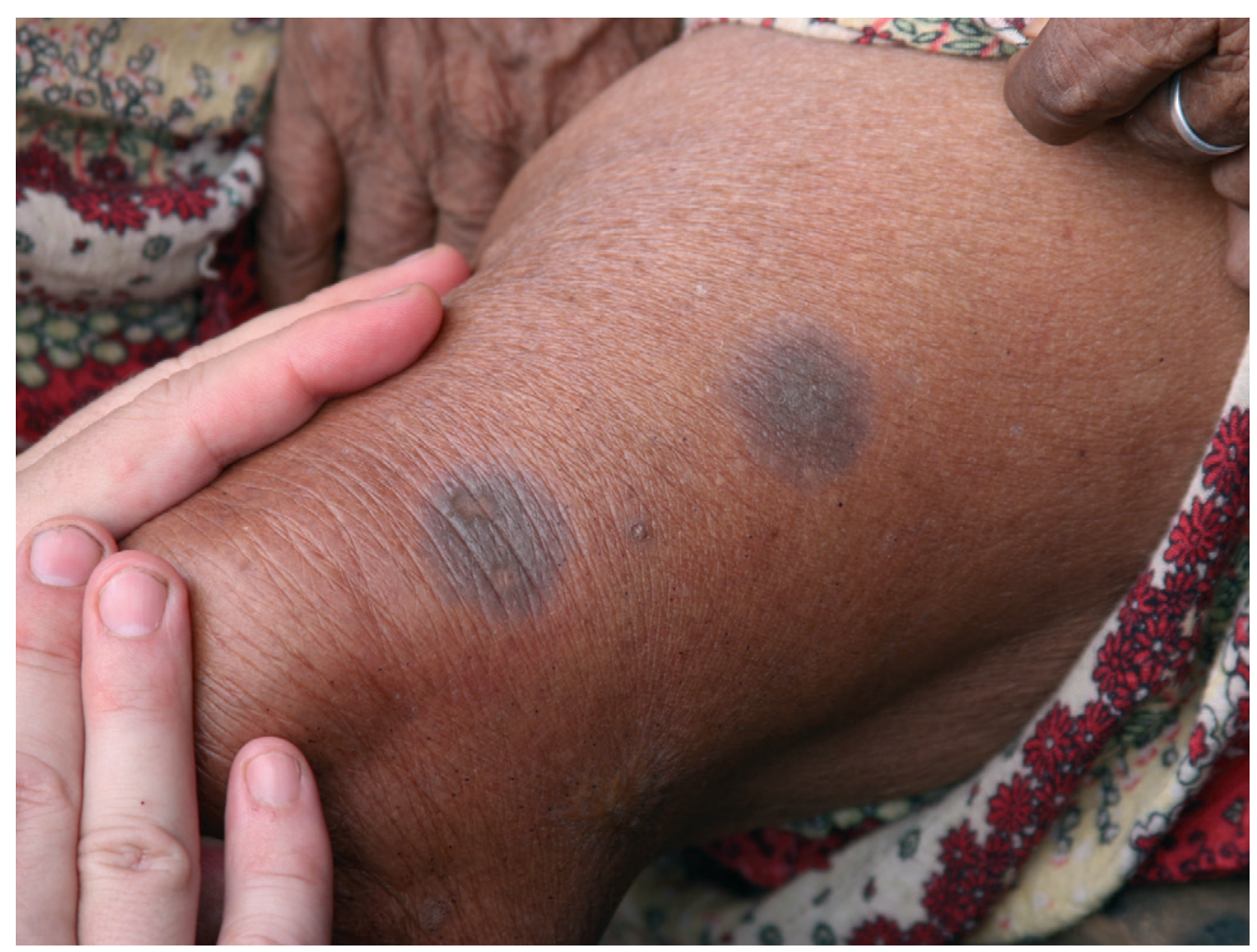

Figura 11. Manchas hipercrômicas na coxa. 


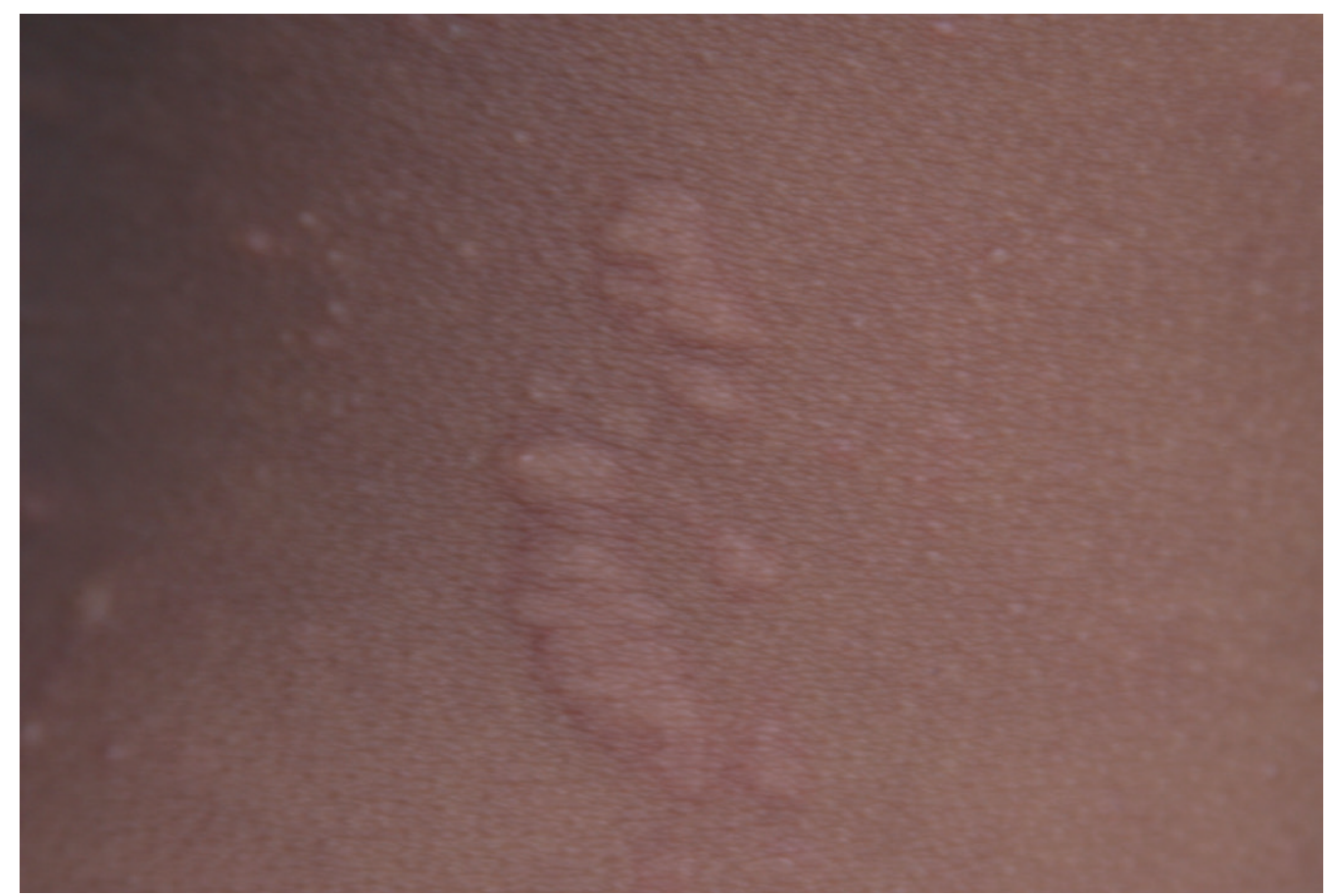

Figura 12. Pápulas e placas edematosas no dorso (edema).

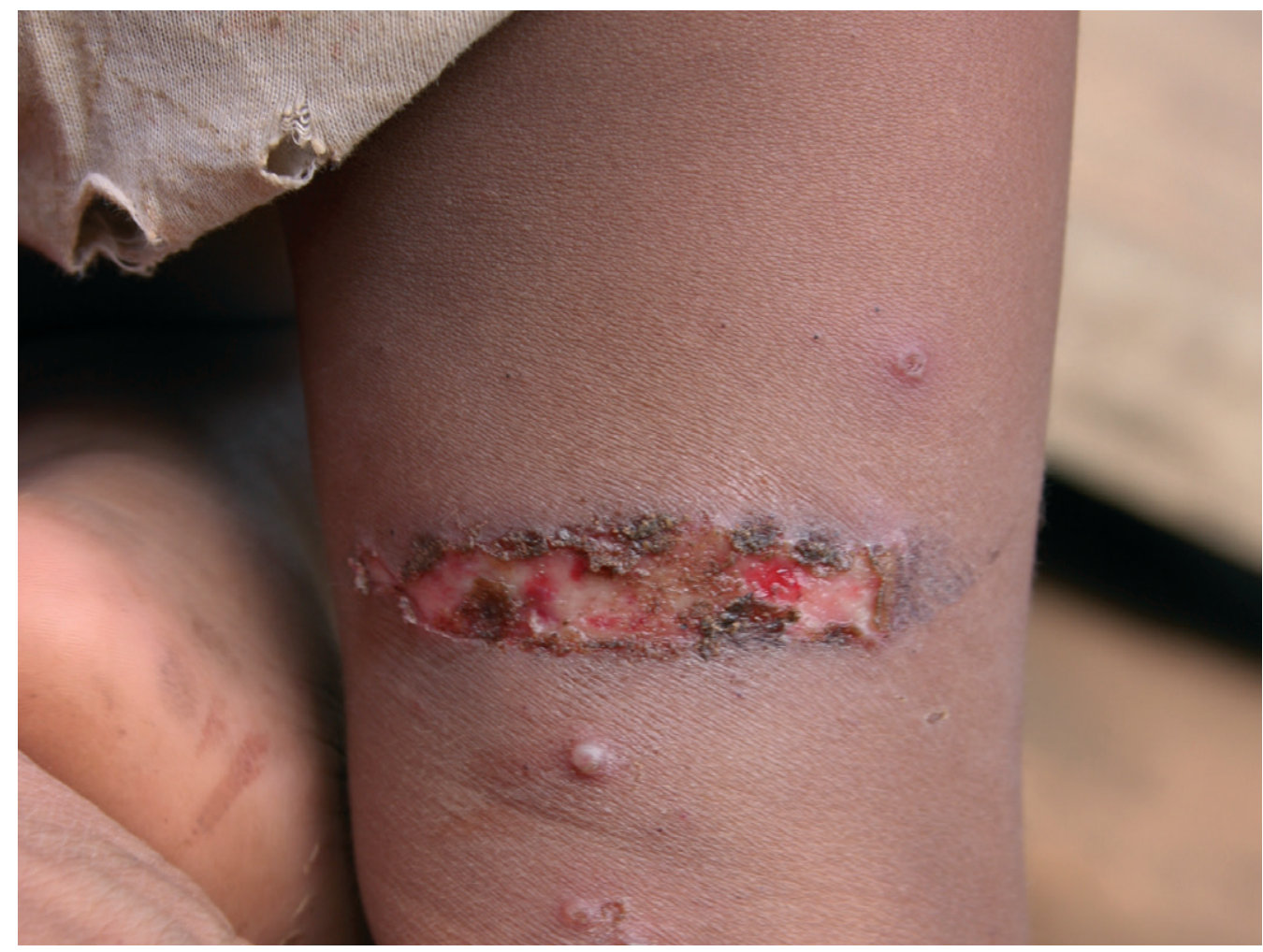

Figura 13. Úlcera na coxa. 


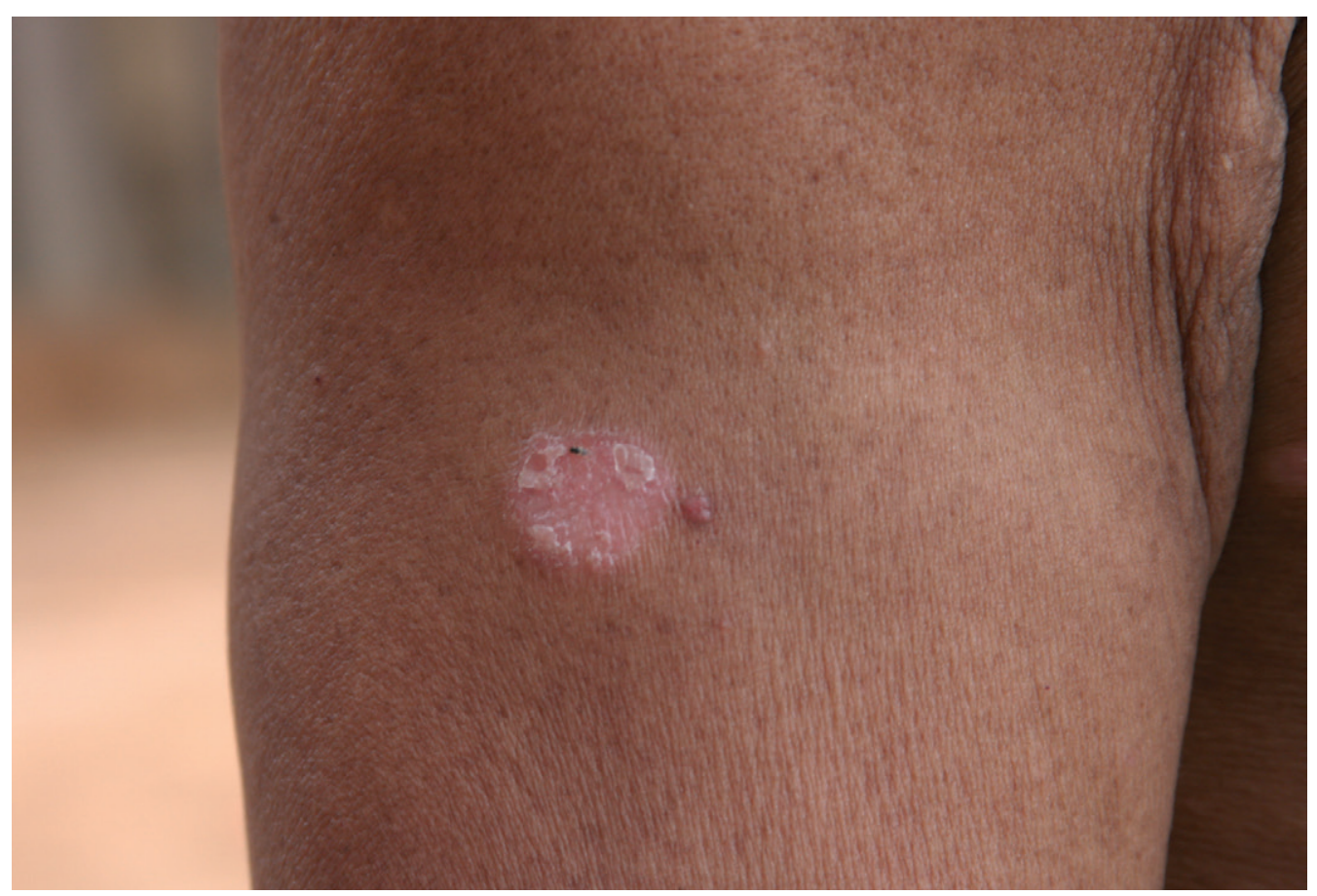

Figura 14. Escama e eritema na perna.

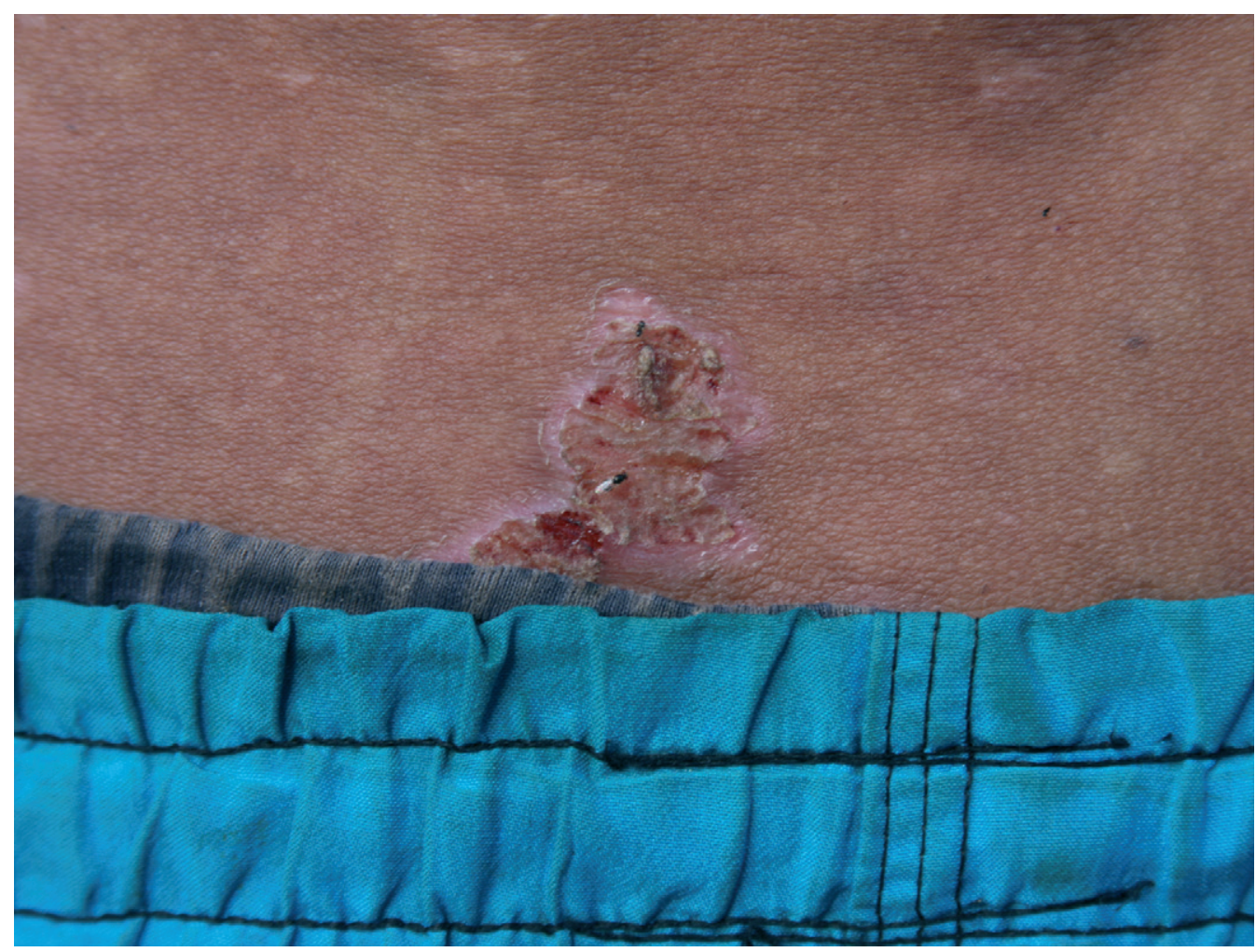

Figura 15. Crostas recobrindo úlcera na região dorsal. 
